\title{
“De Olho no Óleo", vídeo educativo. Tecnologia de inovação para o ensino: relato de experiência
}

"De Olho no Óleo", educational video. Innovation technology for teaching: experience report

"De Olho no Óleo", video educativo. Tecnología de innovación para la docencia: informe de experiencia

Recebido: 28/07/2021 | Revisado: 02/08/2021 | Aceito: 04/08/2021 | Publicado: 09/08/2021

\author{
Aline Viviane de Oliveira \\ ORCID: https://orcid.org/0000-0002-9155-8741 \\ Fundação de Apoio à Escola Técnica, Brasil \\ E-mail: alinevivianeoliveira@yahoo.com.br \\ Carlos Marcelo Balbino \\ ORCID: https://orcid.org/0000-0003-0763-3620 \\ Universidade Federal Fluminense, Brasil \\ E-mail: carlosbalbino@id.uff.br \\ Graziele de Almeida Rocha \\ ORCID: https://orcid.org/0000-0002-7604-3352 \\ Universidade Estácio de Sá, Brasil \\ E-mail: graziin@hotmail.com \\ Pedro Paulo Corrêa Santana \\ ORCID: https://orcid.org/0000-0002-4470-9746 \\ Centro Universitário Anhanguera, Brasil \\ E-mail: psantana.uff@gmail.com
}

\begin{abstract}
Resumo
Este artigo teve como objetivo caracterizar o processo de criação do vídeo educativo De Olho no Óleo e como este vídeo pode servir de exemplo para novas estratégias de ensino de perfil fácil e funcional. Trata-se de um relato de experiencia. Ao Elaborar estratégias de ensino que viabilizem a construção do conhecimento tem sido uma alternativa constante no ensino de ciências. Este trabalho mostrou uma iniciativa relativamente simples de criação de um vídeo como opção de difusão de informação educacional. A meta de desenvolvimento foi gerar material educativo para elucidar as formas corretas de descarte e processamento de óleo doméstico. O processo mostrou que ferramentas de ensino simples podem se tornar inovadoras na prática.
\end{abstract}

Palavras-chave: Aprendizagem; Tecnologia educacional; Filme e vídeo educativo; Óleos.

\begin{abstract}
This article aimed to characterize the process of creating the educational video De Olho no Óleo and how this video can serve as an example for new teaching strategies with an easy and functional profile. It is an experience report. By developing teaching strategies that enable the construction of knowledge, it has been a constant alternative in science education. This work showed a relatively simple initiative to create a video as an option for disseminating educational information. The development goal was to generate educational material to elucidate the correct ways to dispose and process domestic oil. The process showed that simple teaching tools can become innovative in practice.
\end{abstract}

Keywords: Learning; Educational technology; Educational film and video; Oils.

\section{Resumen}

Este artículo tuvo como objetivo caracterizar el proceso de creación del video educativo De Olho no Óleo y cómo este video puede servir de ejemplo para nuevas estrategias de enseñanza con un perfil fácil y funcional. Este es un informe de experiencia. Al desarrollar estrategias de enseñanza que posibiliten la construcción de conocimiento, ha sido una alternativa constante en la enseñanza de las ciencias. Este trabajo mostró una iniciativa relativamente simple para crear un video como una opción para difundir información educativa. El objetivo de desarrollo era generar material educativo para dilucidar las formas correctas de eliminar y procesar el aceite doméstico. El proceso demostró que las herramientas de enseñanza simples pueden volverse innovadoras en la práctica.

Palabras clave: Aprendizaje; Tecnología educativa; Cine y video educativos; Aceites. 


\section{Introdução}

Este texto busca demonstrar como uma iniciativa relativamente simples pode servir como ponto de partida para discussão de temas e problemáticas atuais em sala de aula.

Pode parecer insignificante um gesto diferenciado de um educador, porém, a contribuição que pode advir de tal gesto pode ter impactos significativos na formação e construção do perfil de um discente. Fala-se no ambiente escolar quase exclusivamente dos conteúdos a serem aplicados esquecendo-se algumas vezes a aplicabilidade e responsabilidade prática e social de um ambiente formador (Mesquita-Pires, 2016).

$\mathrm{O}$ ato de ensinar é antigo. Arte e ensino têm caminhado juntos durante gerações e é possível perceber este entrosamento em materiais de didático gerados a partir de gravuras, sons, vídeos e expressões corporais diversas (Lima \& Lima, 2019).

Este relato se originou de uma proposta de desenvolvimento de uma oficina pedagógica pelos alunos do Mestrado em Ensino de Ciências da Saúde e Meio Ambiente. Dentre as diversas opções o grupo de trabalho optou por gerar um material de didático de fácil utilização e que possibilitasse ação direta sobre uma problemática cotidiana, o descarte adequado do óleo de uso doméstico.

Após diversas discussões no grupo foi criado um vídeo educativo com a meta de elucidar as formas corretas de descarte e processamento de óleo doméstico. Este processo mostrou que ferramentas de ensino simples podem se tornar tecnologias inovadoras na prática e proporcionar ao discente um novo caminho para a construção do conhecimento, Inovação é a "introdução de novidade ou aperfeiçoamento no ambiente produtivo ou social que resulte em novos produtos, processos ou serviços", ou seja, inovar é explorar novas ideias por intermédio de conexões, interações e influências com vistas a solucionar demandas inerentes às pessoas e locais para o qual a inovação será destinada (Balbino et al., 2020).

Nos dias de hoje, essas tecnologias podem proporcionar maior acesso e mais informações tanto para os profissionais como para a população em geral, dependendo da linguagem empregada, melhorando também a interação entre equipe e usuários (Prevedello et al., 2020).

A transmissão do saber é tão antiga quanto à humanidade. A concepção de educação varia com o perfil social dos indivíduos e suas necessidades, cabendo a adaptação e busca de soluções e tecnologias inovadoras para melhoria do ambiente comunitário através da implementação de práticas pedagógicas eficazes (Camillo \& Medeiros, 2018).

Problemas recentes como o desequilíbrio ambiental e a busca por sustentabilidade para adequação da vida moderna pode levar educadores a repensar o formato do ensino e as ferramentas utilizadas para o mesmo. É de suma importância que os profissionais se conscientizem das possibilidades que possuem para o alcance da qualidade no ensino e consequentemente na formação de cidadãos.

O consumo de combustíveis fósseis no mundo gera danos diversos ao meio ambiente (Bezerra et al., 2018). Óleos vegetais e animais ou os resíduos de óleos de cozinha constituem as principais matérias-primas utilizadas para a produção de um novo combustível (Ramos et al, 2017), o biodísel é uma alternativa atraente para solucionar esta problemática, pois é biodegradável, atóxico e de características renováveis.

Considera-se que a ferramenta educativa poderá contribuir para o cotidiano dos professores, dando-lhes suporte no processo de ensino-aprendizagem de alunos, visto que, quanto maiores os conhecimentos sobre o descarte adequado de óleo, menores serão os impactos causados ao meio ambiente.

O objetivo deste artigo é caracterizar o processo de criação do vídeo educativo De Olho no Óleo, que dispõe sobre o descarte correto do óleo doméstico, e como este vídeo pode servir de exemplo para novas estratégias de ensino de perfil fácil e funcional. 


\section{Metodologia}

Trata-se de um estudo descritivo de caráter qualitativo, do tipo relato de experiência (Pereira et al., 2018) no desenvolvimento de um vídeo educativo onde se buscou a melhor forma de integrar e disseminar a informação, gerando vinculo e reciprocidade entre educando e o conteúdo.

Ao abordar a criação de uma ferramenta didática voltada para um tema especifico foi preciso definir as vertentes centrais do projeto. Foi definido pelo grupo um tópico relevante a ser desenvolvido, a forma que tal informação seria trabalhada e o público alvo de todo este processo de criação.

Após proposta de desenvolvimento da oficina pedagógica pela disciplina de Prática Docente Supervisionada do Mestrado Profissional em Ensino em Ciências da Saúde e do Meio Ambiente (MECSMA) e discussões diversas pensamos em um tema específico que fosse uma problemática comum a todos os indivíduos e cuja solução pudesse ter apresentação positiva no quesito de responsabilidade/sustentabilidade social.

O tema selecionado foi o descarte de óleo doméstico, situação presente em todos os lares e de consequências ambientais significativas quando realizada de forma incorreta. Ao analisar as formas de descarte corretas e incorretas o grupo começou a selecionar opções sobre como abordar o tema com os alunos optando finalmente pela criação de um vídeo educativo.

Todos os atores participantes do vídeo eram alunos componentes do grupo da atividade proposta na disciplina Prática Docente Supervisionada do MECSMA.

O vídeo deveria possuir duração máxima de 10 minutos para não se tornar maçante aos alunos, ter linguagem fácil e ilustrativa e ser prioritariamente direcionado ao público escolar e adolescente que poderiam agir diretamente sobre os familiares auxiliando no descarte correto do material.

A oficina foi denominada "De Olho no Óleo" e seus objetivos foram: demonstrar a importância do descarte correto do óleo doméstico, a relevância desta prática para o desenvolvimento social sustentável, identificar a maneira correta de descarte do produto, além de informar como realizar o descarte correto deste material através da reciclagem.

Durante a produção do vídeo o grupo chegou à conclusão que a melhor forma de fazer a informação chegar aos alunos seria se eles formassem uma conexão direta com o conteúdo, como iguais. Para tanto optou-se por escolher uma criança como porta voz do conteúdo facilitando a compreensão e a empatia por parte dos educandos.

Além de optar por uma face infantil foi fundamental trazer a questão central para o ambiente familiar e as consequências de hábitos rotineiros. Além de abordar o descarte incorreto do óleo doméstico foi abordada a reciclagem deste material através de estações de coleta e tratamento e os benefícios do processo para a sociedade e para o Meio Ambiente.

A abordagem do vídeo é lúdica, utilizando uma repórter mirim (fillha de um dos integrantes do grupo) e seu cotidiano para explanar sobre a transformação de óleo comum em biodiesel, retratando desde o consumo doméstico até a transformação do produto realizada pela cooperativa de Coletores de Óleo de Volta Redonda - RJ (denominado projeto ECOÓLEO).

O primeiro passo adotado depois da escolha do tema e formato do produto foi definir o roteiro, que deveria ser simples e eficaz focado nas personagens e cenários (Quadro 1) e cenas (Quadro 2). 
Quadro 1: Roteiro do Vídeo De Olho no Óleo.

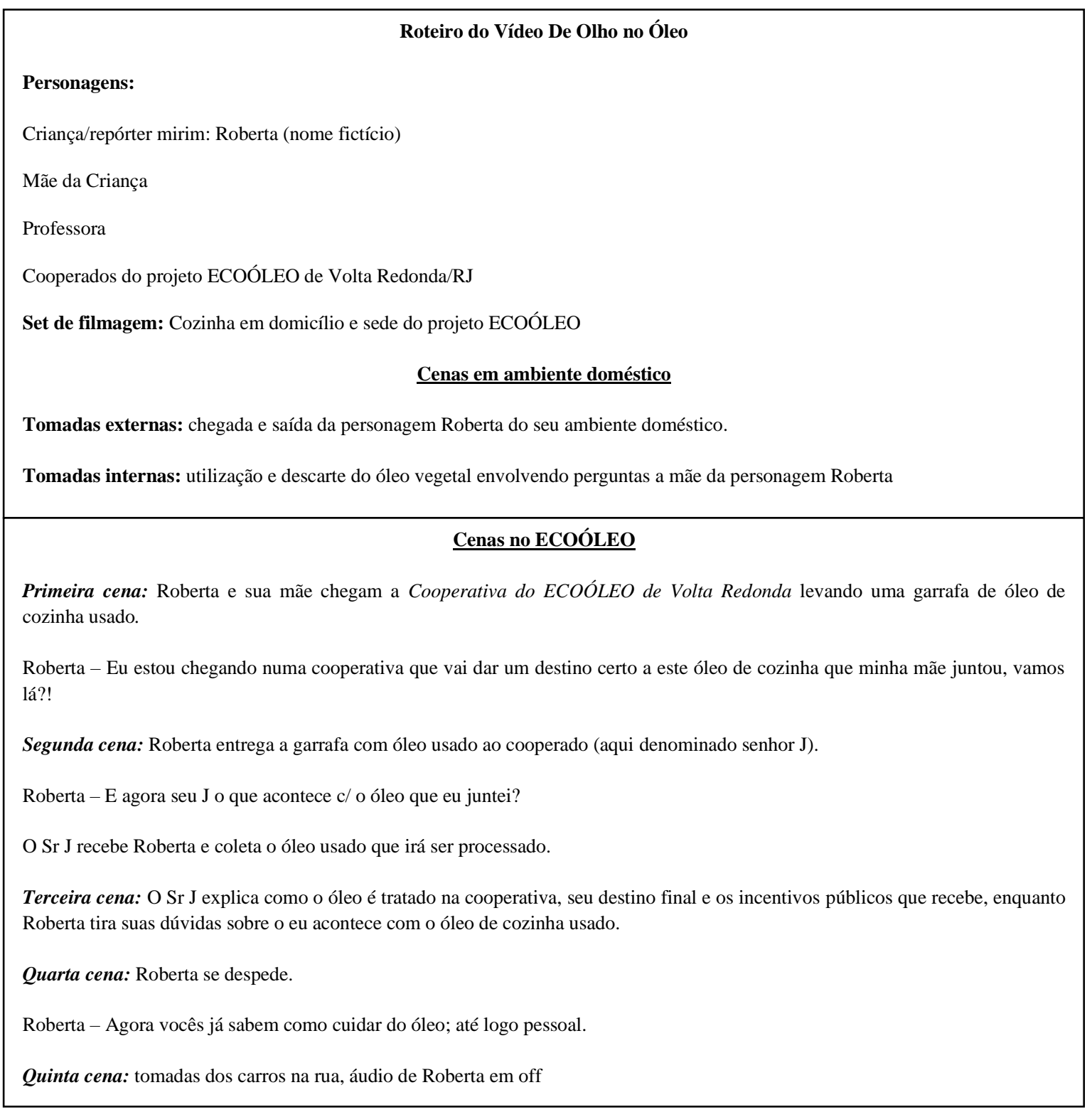

Fonte: Autores.

As personagens foram interpretadas por integrantes do grupo, pelos cooperados do ECOÓLEO como eles mesmos e pela filha de uma das mestrandas do MECSMA. Todos os participantes do vídeo assinaram a documentação de direito de imagem, além de a menor receber autorização por escrito da responsável para participar.

Além da geração do conteúdo áudio visual foi gerada uma logo representativa do projeto (Figura 1) para que o mesmo pudesse ser facilmente identificado dentre demais oficinas em execuções e/ou durante eventos. 
Figura 1: Logo De Olho no óleo.

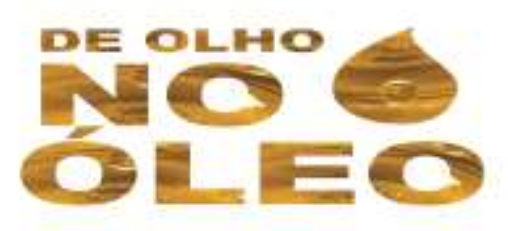

Fonte: Designer gráfico - Patrícia S. Rocha Alves

Foram desenvolvidos slides em Power Point para explanação de informações básicas sobre o tema de descarte de óleo vegetal e fases específicas que integradas garantem a execução do projeto conforme as expectativas em um tempo de aproximadamente 45 minutos (corresponde a 1 tempo de aula na Educação Básica). Foram adotados materiais como: Formulários impressos, canetas, material áudio visual compatível com a reprodução do vídeo e Power Point.

A primeira fase foi denominada Fase de Explanação onde se aborda a compra e utilização do óleo de cozinha nos domicílios e questiona-se aos educandos sobre o que é feito com este tipo de resíduo em seus lares, com relação ao descarte, através de Power Point. (Duração: 10 minutos). Na segunda fase acontece a apresentação do vídeo De Olho no Óleo com duração de 9 minutos voltados para o ensino da reciclagem do óleo vegetal e a importância deste ato para o meio ambiente. Neste momento é importante que os alunos percebam e possam ter consciência do descarte correto deste resíduo. Na terceira fase (Fase de Avaliação) é distribuído um formulário (que não deve ser identificado) em meia folha de A4 com desenho de uma gota de óleo para que os alunos relatem como o descarte do óleo pode ser modificado em suas residências e quais os aspectos positivos desta ação (esta fase tem duração aproximada de 15 min.). Na quarta e última fase, (Fase da Discussão) os alunos são provocados em uma conversa informal sobre o tema e seus pontos positivos e negativos embasados em algumas opiniões dos formulários por cerca de $10 \mathrm{~min}$.

Após todas as etapas de criação o produto final foi uma ferramenta educativa versátil e de fácil aplicabilidade desde que o educador possua acesso a equipamento áudio visual. Com o intuito de gerar um material didático o grupo acabou por perceber que algumas vezes mais importante que o produto em si é o benefício que o mesmo pode oferecer aos educandos.

O vídeo foi desenvolvido com apoio de profissionais do Departamento de marketing da instituição que ministra o curso de MECSMA.

Não houve a necessidade de submissão a Comitê de Ética em Pesquisa devido a Resolução Brasileira não considera este projeto pesquisa envolvendo seres humanos (Amorim, 2019) e, portanto, não passam por avaliação do Sistema CEP/CONEP os seguintes casos: Estudos de Gestão e Melhoria de Processos, estudos em que o foco está voltado a melhoria de um processo já existente no setor ou entender as práticas de gestão do ambiente. Vale ressaltar que nestes estudos, o objeto de avaliação não é o ser humano e sim informações administrativas do local a ser analisado.

\section{Resultados e Discussão}

Diante da problemática e da proposta de oficina pedagógica foi criado o produto "De Olho no Óleo" um vídeo educativo para orientar crianças e adolescentes sobre o descarte correto deste produto tão nocivo ao meio ambiente. Após a finalização do vídeo foi necessário a elaboração da oficina pedagógica como requisito para obtenção de nota para a obtenção de aprovação na disciplina que propôs a atividade, o vídeo foi onde o mesmo seria trabalhado. 
Aplicabilidade e Desenvolvimento

A sustentabilidade não engloba somente a extração de recursos naturais de forma responsável engloba também a destinação adequada de resíduos gerados. No processo de sustentabilidade é importante perceber a forma como os atores do meio exercem sua responsabilidade perante questões ambientais e de como as ações desenvolvidas podem beneficiar a geração atual e as gerações futuras (Teixeira et al., 2016).

Um meio significativo de atingir a população é através da disseminação de informação. Indivíduos jovens geralmente possuem a capacidade de informar um grande número de pessoas por meio de suas famílias, amigos e vizinhos, o que potencializa a socialização do conhecimento.

O óleo de cozinha é de origem vegetal, e é extraído em geral dos frutos de plantas denominadas "oleaginosas". Altamente prejudicial ao meio ambiente quando descartado de forma incorreta (Geralmente diretamente nas redes de esgoto doméstico) pode ser considerado um problema, causando grandes impactos ambientais por seu potencial poluidor para mananciais e demais fluxos fluviais (Dias et al.,2020).

A qualidade de recurso finito dos combustíveis fósseis encorajou a busca de substitutos para os derivados do petróleo, o resultado desta busca foi o combustível denominado Biodiesel (Santos \& Ferreira Filho, 2017). Produtos de óleos vegetais são os melhores substitutos para o diesel tradicional, pois não demandam nenhuma modificação nas máquinas movidas por este combustível e tem alto poder energético (Batista, 2014).

Uma das metas dos Objetivos de Desenvolvimento do Milênio é integrar os princípios do desenvolvimento sustentável nas políticas e programas e reverter a perda de recursos ambientais (Roma, 2019). Em alguns países existem normas estabelecidas para o descarte de óleos utilizados para fritura (Borjes et al., 2014), mas no Brasil não existem leis e regulamentações que estabeleçam limites para as alterações destes óleos (Cunha \& Trancoso, 2013)

O Governo do Estado possui um Programa de Reaproveitamento de Óleos Vegetais do Estado do Rio de Janeiro (Prove) que foi criado em 2008, pela Secretaria de Estado do Ambiente (SEA/RJ), com o objetivo de evitar o despejo de óleo de cozinha usado em corpos hídricos, ao estimular sua coleta e a reutilização na produção de sabão e de fontes alternativas de energia, como o biodiesel.

Existe um projeto em pleno funcionamento em uma cidade do interior do Estado do Rio de Janeiro o ECOÓLEO que oferta solução viável para a problemática do descarte do óleo doméstico evitando assim a poluição de rios e mares e consequentemente dano a fauna e flora aquáticas, além de coibir a impermeabilização do solo e a produção de gás metano quando o produto entra em decomposição. O município implementou o projeto do ECOÓLEO oferecendo destinação adequada ao óleo de cozinha da cidade auxiliando assim no combate da poluição causada pelo descarte indevido do produto.

O trabalho de reciclagem dos resíduos é gerido pela Associação de Coletores de Resíduos Líquidos e Sólidos. Através do trabalho da cooperativa do ECOÓLEO litros de óleo de cozinha usados são captados em estabelecimentos comerciais e escolas (atualmente o projeto conta com a participação de 130 escolas) e transformados em combustível no formato de biodiesel gerando nova aplicabilidade para um produto poluidor e diminuindo ainda a utilização de combustíveis fósseis.

Apesar desta iniciativa e de outras semelhantes a esta em outros municípios é provável que boa parte das pessoas desconheça o que fazer com o óleo de cozinha a ser descartado, o que faz com que o mesmo seja eliminado na rede de esgoto comum que muitas vezes não possui qualquer tipo de tratamento.

O óleo vegetal compromete as tubulações dos edifícios e das redes de tratamento de esgoto (Oliveira \& Gonçalves, 2016). Além do aspecto ambiental, o existe a necessidade do incentivo a criação de cooperativas de coleta seletiva de resíduos sólidos e líquidos no caso, o óleo de cozinha e a geração de trabalho e renda para os catadores organizados, pois é preciso a mobilização de pessoal para fazer a coleta e mão de obra nas fábricas que fazem a transformação deste resíduo (Miguel \& Franco, 2016). 
A oficina foi desenvolvida em uma escola pública seguindo-se as fases do projeto anteriormente descritas. Durante a execução da mesma percebeu-se que as informações expostas no ambiente educacional são de grande valia, principalmente quando utilizamos tecnologias e ações de entretenimento, pois aproxima os educandos das informações trabalhadas no cotidiano.

Pode ser muito difícil para um educador trabalhar uma informação partindo do abstrato e talvez seja mais difícil para os alunos assimilarem esta informação se não possuírem formas de contextualizá-las em sua realidade e/ou meios de percepção. Gerir conhecimento tornou-se um imperativo para as organizações que almejam sobreviver à concorrência. Todavia, o desafio é que muitas organizações não detêm uma política de treinamento estruturada ou ainda não dispõem de profissionais preparados para incentivar os colaboradores como deveriam (Martins et al., 2017).

Ao implementar a oficina foi possível notar que o vídeo como ferramenta educativa, de curta metragem e com linguagem de fácil compreensão é um instrumento inestimável ao ensino. Pode parecer uma produção complicada, mas não é. A geração deste tipo de artefato didático, de longa durabilidade, requer apenas criatividade e a sede de solucionar um problema.

Pode-se questionar quanto a obtenção do equipamento de filmagem, que neste caso foi profissional. Existem câmeras de vídeo disponíveis em diversos modelos de aparelhos celulares e máquinas fotográficas ao alcance de boa parte da população, além de ferramentas de edição gratuitas e de fácil utilização disponíveis na internet que podem oferecer ao docente um meio diversificado de apresentar novos conteúdos. Talvez o que se precise para levar uma classe de alunos a um novo patamar pode ser uma câmera, uma ideia e um profissional determinado a vencer barreiras.

Com este trabalho também pode-se ajudar os estudantes a adquirir as capacidades necessárias para utilização tecnologias de informação, buscar, analisar e avaliar informações, solucionar problemas e tomar decisões (Rocha et al., 2019). É preciso fazer com que esses mecanismos ganhem vida dentro da sala de aula (Almeida et al., 2020). Acreditou-se que conseguimos sensibilizá-los quanto à importância da conservação ambiental e também da não reutilização do óleo. É muito importante destacar que essa colaboração efetiva dedicada ao projeto, contribui muito para melhoria e qualidade de vida desses alunos e também para conservação do meio ambiente.

$\mathrm{O}$ vídeo gerado pode ser utilizado a título de informação por qualquer educador ambiental interessado em abordar o tema de descarte com óleo vegetal. Para acesso do grande público o material encontra-se disponível na plataforma Youtube através do link https://www.youtube.com/watch?v=pPobp2O6tIk.

\section{Conclusão}

Percebeu-se que o processo de uma ideia relativamente simples gera um resultado tão satisfatório. Inerente é o fato de que ao realizar um trabalho de qualquer natureza espera-se um resultado positivo, mas quando este resultado oferece mais do que o esperado o projeto em questão pode ser descrito como surpreendente.

Ao criar um vídeo educativo o objetivo era o desenvolvimento dinâmico, de linguagem fácil capaz de incentivar as crianças ao aproveitamento correto de um material utilizado com frequência no cotidiano dos lares e levá-lo a perceber a importância do desenvolvimento sustentável por meio da reciclagem fomentando o exercício social responsável.

Identificar a maneira correta do descarte do óleo usado e informar ao público alvo como realizar o descarte, apenas com uma atividade em sala de aula, possibilitou a descoberta do prazer que atividades de ensino relativamente simples podem trazer quando engajadas com conceitos de responsabilidade social. Existem várias formas de incentivar a cidadania e a sustentabilidade é uma delas. 
Foi percebido que expor somente os malefícios de uma ação contra o Meio Ambiente pode ser uma informação perdida, mas que atrelar a estas questões experiências práticas, neste caso através da oficina de vídeo, oferta resultados melhores e mais significativos no processo ensino-aprendizagem.

O conteúdo foi disposto na rede mundial de computadores para que cada vez mais indivíduos interessados tenham acesso à informação.

Além de relatar o processo de criação de vídeo este texto buscou oferecer aos professores subsídios para a criação de diversos conteúdos em vídeo diversificando o processo de ensino e ofertando aos educandos mais uma forma de alcançar a informação.

Sendo assim, é possível afirmar que o trabalho de desenvolvimento do vídeo educativo "De Olho no Óleo" foi não só útil aos educandos no caráter informativo como também foi gratificante aos professores e ao grupo de trabalho - oficineiros. As atitudes simples podem ter resultados extremamente positivos basta um problema e uma boa ideia, com um pouco de trabalho surgirão resultados inovadores que podem maximizar o processo de ensino gerando vantagens tanto para o educador quanto para os educandos.

Sugere-se o desenvolvimento de novos estudos e pesquisas com o desenvolvimento de novas estratégias permitindo assim uma melhor satisfação durante a atividade laboral dos profissionais educadores, beneficiando o aluno com aumentando a qualidade do aprendizado.

\section{Referências}

Almeida, A. C. F. de, Lopes, L. F. de O., \& Braga, C. B. (2020). Professores Inovadores: mudanças de paradigmas a partir das necessidades apresentadas pelos alunos. Research, Society and Development, 9(7), e576974428. https://doi.org/10.33448/rsd-v9i7.4428

Amorim, K. P. C. (2019). Ética em pesquisa no sistema CEP-CONEP brasileiro: reflexões necessárias. Ciência \& Saúde Coletiva [online], 24(3),1033-40, ISSN 1678-4561. https://doi.org/10.1590/1413-81232018243.35292016.

Balbino, C. M., Silvino, Z. R., Joaquim, F. L., Souza, C. J. de, \& Santos, L. M. dos. (2020). Inovação tecnológica: perspectiva dialógica sob a ótica do Joseph Schumpeter. Research, Society and Development, 9(6), e198963593. https://doi.org/10.33448/rsd-v9i6.3593

Batista, M. M. (2014). Determinação dos parâmetros de solubilidade de óleos vegetais, biodieseis, diesel e blendas biodiesel-diesel. http://repositorio.unicamp.br/jspui/handle/REPOSIP/266089

Bizerra, A. M. C., Queiroz, J. L. A. de, \& Coutinho, D. A. M. (2018). O impacto ambiental dos combustíveis fósseis e dos biocombustíveis: as concepções de estudantes do ensino médio sobre o tema. Revista Brasileira De Educação Ambiental (RevBEA), 13(3), 299-315. https://doi.org/10.34024/revbea.2018.v13.2502

Borjes, L. C., Cecon, G., \& da Silva, A. P. B. (2014). Análise da degradação do óleo de fritura de restaurantes comerciais do centro de ChapecóSC. DEMETRA: Alimentação, Nutrição \& Saúde, 9(3), 833-848.

Camillo, C. M., \& Medeiros, L. M. (2018). Teorias da educação. https://repositorio.ufsm.br/bitstream/handle/1/18360/Curso_Lic-Ed-Camp_TeoriasEduc.pdf?sequence $=1 \&$ is Allowed $=\mathrm{y}$

Cunha, E. S., \& Trancoso, M. D. (2013). A importância da coleta do óleo usado para o meio ambiente. Educ Ambiental em Ação, 44.

Dias, L. C., da Silva, N. C., da Rocha Patrício, P., \& Coutinho, T. D. S. A. (2020). Prática Educacional e Ambiental no ensino de Química para alunos do Ensino Médio: reciclagem do óleo de cozinha e a produção de sabão. Mediação, (10), 65-74.

Lima, I. M. A, Lima, X.M.A. Os paradigmas da educação nas civilizações antigas e a preparação dos pesquisadores da antiguidade. Revista Científica Multidisciplinar Núcleo do Conhecimento. 05, 100-109.

Martins, P. B., Ribeiro, G. L. F., \& Carvalho, J. G. (2017). Contribuições das Comunidades de Prática para o Treinamento e Desenvolvimento de Pessoas. Research, Society and Development, 4(4), 239-250. https://doi.org/10.17648/rsd-v4i4.7

Mesquita-Pires, C. (2016). A Investigação-acção como suporte ao desenvolvimento profissional docente. EduSer-Revista de educação, 2(2). 10.34620/eduser.v2i 2.23

Miguel, A. C., \& Franco, D. M. B. (2016). Logística Reversa do óleo de cozinha usado. http://www. webartigos. com/artigos/logistica-reversa-do-oleo-decozinha-usado/113547/.

Oliveira, M. M \& Gonçalves, M. F. S. (2016). Perspectivas do óleo residual de fritura: uma abordagem econômica, jurídica e socioambiental. Revista ESPACIOS, 37 (25). 
Research, Society and Development, v. 10, n. 10, e253101018840, 2021

(CC BY 4.0) | ISSN 2525-3409 | DOI: http://dx.doi.org/10.33448/rsd-v10i10.18840

Pereira, A. S., Shitsuka, D. M., Parreira, F. J., \& Shitsuka, R. (2018). UFSM. https://repositorio. ufsm.br/bitstream/handle/1/15824/Lic_Compu tacao_Metodologia-Pesquisa-Cientifica. pdf

Prevedello, B. P., Dotto, P. P., \& Santos, B. Z. dos. (2020). Animação no formato de vídeo como tecnologia para a promoção do aleitamento. Research, Society and Development, 9(1), e199911864. https://doi.org/10.33448/rsd-v9i1.1864

Ramos, L. P., Kothe, V., César-Oliveira, M. A. F., Muniz-Wypych, A. S., Nakagaki, S., Krieger, N., \& Cordeiro, C. S. (2017). Biodiesel: matérias-primas, tecnologias de produção e propriedades combustíveis. Revista virtual de química, 9(1), 317-369.

Rocha, P. C. S., Jucá, S. C. S., Silva, S. A. da, \& Monteiro, A. de O. (2019). Competências digitais na perspectiva da informação, conhecimento e aprendizagem. Research, Society and Development, 8(8), e42881241. https://doi.org/10.33448/rsd-v8i8.1241

Roma, J.C. (2019). Os objetivos de desenvolvimento do milênio e sua transição para os objetivos de desenvolvimento sustentável. Ciência e Cultura, 7l(1), 33-39. https://dx.doi.org/10.21800/2317-66602019000100011

Santos, J. A. D., \& Ferreira Filho, J. B. D. S. (2017). Substituição de combustíveis fósseis por etanol e biodiesel no Brasil e seus impactos econômicos: uma avaliação do Plano Nacional de Energia 2030. http://repositorio.ipea.gov.br/bitstream/11058/8231/1/PPE_v47_n03_Substitui\%C3\%A7\%C3\%A3o.pdf

Teixeira, N. F. F., Moura, P. E. F., Coelho, F. A., \& de Andrade Meireles, A. J. (2016). Práticas de eduação ambiental e sustentabilidade aplicadas a formação da cidadania. Revista Geográfica Acadêmica, 10(2), 30-40. 